Www.iseis.org/jei

\title{
Saving Water and Associated Energy from Distribution Networks by Considering Landscape Factors in Pressure Management and Use of District Metered Areas
}

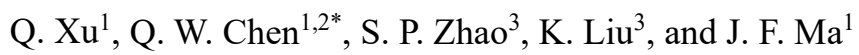 \\ ${ }^{1}$ Key Laboratory of Drinking Water Science and Technology, Research Center for Eco-Environmental Sciences, \\ Chinese Academy of Sciences, Shuangqinglu 18, Beijing 100085, China \\ ${ }^{2}$ Center for Eco-Environmental Sciences, Nanjing Hydraulic Research Institute, Guangzhoulu 223, Nanjing 210029, China \\ ${ }^{3}$ Beijing Waterworks Group, Xuanwumen West Street 121, Beijing 100031, China
}

Received July 29, 2014; revised May 4, 2015; accepted February 16, 2016; published online March 14, 2017

\begin{abstract}
Controlling water loss in distribution systems is attracting increasing interest due to our increasingly limited water resources, exacerbated by rapid population growth, fast urbanization and climate change. Much has been invested in the management of water distribution networks to reduce water loss. However, the efficiency of management measures depends on spatiotemporal patterns of water loss, which are significantly influenced by the urban landscape. It is therefore important to consider urban landscape factors when designing and operating water distribution networks in order to reduce water loss and energy consumption. We investigated how the urban landscape, in particular urban topography and layout of water end users, impacts water loss and energy consumption. Topography was found to significantly influence the spatial pattern of average water pressure, while layout of end users influenced temporal variation of water pressure. A two-level water distribution network operating scheme (PMZ-DMA) was proposed to account for the influences of the two urban landscape factors. Application of the scheme efficiently reduced water loss, thereby generating significant environmental benefits, including reduction of energy consumption and greenhouse gas emissions.
\end{abstract}

Keywords: water loss control, water distribution network, urban landscape, energy consumption reduction, greenhouse gas emission reduction

\section{Introduction}

Freshwater resources are becoming increasingly limited due to rapid world population growth, fast urbanization and global climate change. According to the United Nations, more than one in six people do not have access to safe water. By 2025, 1.8 billion people will live in countries or regions with absolute water scarcity, and two-thirds of the world's population will be under water-stressed conditions (WWAP, 2006). World energy is also facing a similar situation, with annual global energy consumption increasing by $16.4 \%$ from 2004 to 2011 (available from: http://data.worldbank.org/indicator/EG. USE.COMM.KT.OE/countries/1W?display=graph). If the reserves of energy are assumed to be constant, annual energy consumption growth will impose great pressure on global sustainable development. Along with energy consumption, climate change has further intensified. Therefore, the necessity for water and energy conservation and their efficient use must be recognized and prioritized worldwide.

\footnotetext{
* Corresponding author. Tel.: +86 2585829765; Fax: +86 2585829765. E-mail address: qchen@rcees.ac.cn (Q. W. Chen).
}

ISSN: $1726-2135$ print/1684-8799 online

(C) 2018 ISEIS All rights reserved. doi:10.3808/jei.201700361
To cope with water scarcity and uneven distribution, efficient water resources management has been emphasized. Relevant studies include water resources allocation (Wang et al., 2003), water resources management policy ( $\mathrm{Su}$, et al., 2013), water resources trade (Luo et al., 2003), management modelling of water resources systems (Xu, et al., 2012; Rahmani and Zarghami, 2015), and planning of regional water resources systems (Olsen et al., 2006; Li, et al., 2006, 2009, 2011; Lv, et al., 2010). These studies provide in-depth knowledge of efficient water resources management from the supply side. However, equal emphasis should be put on the demand side to improve the efficacy of water use. One primary idea is to reduce the water loss during transport and distribution.

Each year more than 32 billion $\mathrm{m}^{3}$ of potable water is lost from water distribution networks all over the world, which is about $35 \%$ of total water supplied and equivalent to the amount of water consumed by 200 million people each year (Farley et al., 2008). Water supply is an energy-intensive industry, and water loss contributes to considerable energy waste. Energy is consumed during collection, conveying and treatment of source water and through distribution of treated water to end users (GEI Consultants / Navigant Consulting Inc., 2010a, b). About 2-42 MJ of energy is needed to treat and distribute $1 \mathrm{~m}^{3}$ of water, although differences exist in the 
energy consumption rate depending on the source of water (Friedrich, 2002; Racoviceanu et al., 2007; Cai et al., 2009a, b; Lyons et al., 2009; Stokes and Horvath, 2009; Mo et al., 2011). According to James et al. (2002), 2-3\% of total world energy is consumed by the water industry. Therefore, if water loss from the distribution network is well managed, water and energy stress can be alleviated to some extent. Along with energy saving, greenhouse gas emissions can also be reduced (Stokes and Horvath, 2006; Stokes et al., 2013). Policy makers, researchers and practitioners have initiated efficient water use practices in urban management, as demonstrated by the emergence of water-sensitive cities and water-sensitive urban development (Coombes et al., 2000; Wong and Brown, 2009; Morison and Brown, 2011; Ferguson et al., 2013).

Water loss can be reduced through many approaches (Puust, 2010; Mutikanga et al., 2013; Xu et al., 2014b). Water loss is basically dependent on two factors, that is, pipe breaks and water pressure. Water loss can therefore be mitigated either by reducing pipe breaks or by lowering water pressure or by both. Pipe breaks can be decreased by pipe break detection, repair, pipe rehabilitation and replacement, while water pressure can be lowered by regulating pumps and pressure reducing valves (PRVs). The effective application of these primary approaches has been investigated for optimal water loss reduction. Such research includes prediction and localization of pipe breaks (Misiunas et al., 2005; Berardi et al., 2008; Park et al., 2008; Aksela et al., 2009; Wu, 2009; Carrión et al., 2010; Islam et al., 2011; Xu et al., 2011a; b), optimization of pipe rehabilitation/replacement time (Shamir and Howard, 1979; Park and Loganathan, 2002; Luong and Nagarur, 2005; Dridi et al., 2009; Park et al., 2010; Fan and Huang, 2012; Tabesh and Saber, 2012; Fontana and Morais, 2013; Xu et al., 2013), and management of water pressure (Reis et al. 1997; Lambert, 2000; Araujo et al., 2006; Marun- ga et al., 2006; Girard and Stewart, 2007; Nazif et al., 2010; Xu et al., 2014a).

To effectively design a water loss control plan, factors influencing the behaviour of water pressure and occurrence of pipe breaks must be emphasized. One of the most important is the urban landscape, especially urban topography and water user layout. Water pressure in a pipe is a function of ground elevation and flow. In other words, given the inlet pressure, pipe water pressure is determined by urban topography (which usually determines pipe elevation) and water demand characteristics associated with the pipe (i.e., water flow). Pipe breaks are also influenced by urban landscape factors such as land use types, traffic loads and soil properties (Doleac et al., 1980). In summary, the urban landscape is a non-negligible factor affecting water loss from water distribution networks.

Landscape factors are usually included in the design of water supply systems during urban planning. Quantities and locations of water plants are determined according to water availability and the dimensions of the city (Ontario Ministry of the Environment, 2008). Once installed, the water supply system will serve for decades. However, cities may continue to expand and further influence water bodies, especially in developing countries (Du et al., 2010). As a result, the size of a water distribution network increases continuously, and management becomes more difficult as the network increases in complexity. Researchers and practitioners have studied ways to solve this problem. An effective solution is to partition (isolate) a complex network into many simple subnetworks, known as DMA (District Metered Areas), by closing boundary valves. There are very few, usually only one, inlets to a DMA. Flow meters are installed at the inlets to monitor DMA flow, based on which DMA performance can be assessed and water loss can be detected (Buchberger and Nadimpalli, 2004).

The partitioning of a network is generally based on empirical approaches. However, researchers have also tried using new algorithms to support DMA design. Among these algorithms, graph theory is the most often applied, and has been used to help identify the position of flow meters and the boundary valves that need to be closed (Di Nardo and Di Natale, 2011). From this, the reliability of a water supply network can be analyzed (Di Nardo et al., 2014) and the compromise between robustness required for DMA design and different decision options can be made to reduce total cost (Gomes, 2013). Based on pipe network partitioning, water pressure management strategies can be optimized. For example, Sousa et al. (2014) proposed a method to optimize pump control and PRV settings and applied it to a real network. A good balance between the benefits (reduction of water loss and electricity consumption) and the costs (investment for PRV installation) was obtained. Network partitioning can facilitate water pipe network management, especially in terms of water pressure.

However, management of a water distribution network is especially complex in developing countries, because the networks are usually not well configured and often expand with rapid urbanization. As the largest developing country in the world, China is facing this challenge. In the past several decades, China has seen rapid urbanization, together with the rapid development of water distribution networks. For example, the total pipe length of the urban water distribution networks in China increased at a speed of $78.9 \mathrm{~km}$ every day from 2004 to 2013 (National Bureau of Statistics of China: http://data.stats.gov.cn/). The introduction of new pipes or subsystems into existing pipe networks can significantly change the hydraulic performance of a network; however, in most cases, this point is neither realized in the design phase nor emphasized in the daily management of water supply. In recent years, scientific management of water pipe networks has attracted increasing interest in China. Although the importance of water leakage detection optimization, pipe network partitioning, and water pressure management is well recognized, many difficulties still exist, such as the lack of accurate information on pipe networks and water use, which could be used to support detailed hydraulic analysis of the pipe network and to optimize water loss control strategies. This difficulty has been magnified by the looping characteris- tics of most of China's water distribution networks. Thus, there is a great need for instructive methodologies of water network management for developing countries such as China.

Although some urban landscape factors have already been incorporated into water loss control in practice, for example, physically or hydraulically dividing a pipe network into many small, relatively independent zones based on ground 
elevation, water user characteristics, urban water bodies, main roads and other urban landscape elements, the relationship between water supply management and urban landscape has not been investigated in detail. The objectives of this study were to: (1) investigate the relationship between potential water loss (and associated energy consumption) and urban landscape factors, particularly urban topography and water user layout; (2) develop a two-level water distribution network management scheme (PMZ-DMA) and apply it in a real-world water distribution network.

\section{Methodology}

\subsection{Pipe Network Management Considering Impact of Urban Topography}

Water pressure requirements of end users are closely related to urban topography. Users in high elevation locations require larger water head, which means water plants need to expend greater energy to satisfy the water requirements at these critical point locations. In a pipe network, if the requirements of the critical point location are satisfied, excess water pressure may exist in pipes located closer to the water plant or in lower areas, consequently resulting in water loss and energy waste.

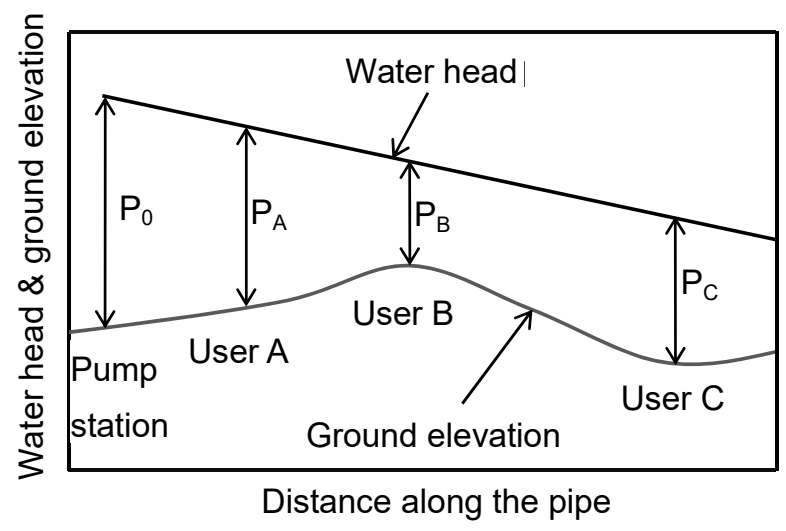

Figure 1. Relationship between water pressure and ground topography.

Taking the simplest water distribution network, a single pipe with a pump station and three users, as an example, Figure 1 gives the water head and pressure changes along the pipe. The water head in the pipe decreases monotonically from the pump station to users $\mathrm{A}, \mathrm{B}$ and $\mathrm{C}$ following an increase in distance. However, the changes in pipe pressure are not necessarily monotonic because of the variation in topography. In Figure 1, $\mathrm{P}_{0}$ represents the pressure at the pump station, and $\mathrm{P}_{\mathrm{A}}, \mathrm{P}_{\mathrm{B}}$ and $\mathrm{P}_{\mathrm{C}}$ are the pressures at users $\mathrm{A}, \mathrm{B}$, and $\mathrm{C}$, respectively. User $\mathrm{B}$ has the minimum pressure because it has the highest elevation compared with the other two users. Therefore, this point becomes the critical point in the system. Pressure $\mathrm{P}_{0}$ at the pump station should be regulated to satisfy the water demand of user $\mathrm{B}$. However, pressures $\mathrm{P}_{\mathrm{A}}$ and $\mathrm{P}_{\mathrm{C}}$ may be at a higher level than necessary, leading to water loss and higher risk of pipe burst. If pressure $\mathrm{P}_{0}$ is reduced to cut the excess pressure at user A and user C, user B may have insufficient pressure. There are two alternative solutions to overcome this dilemma. One is to reduce $\mathrm{P}_{0}$ but increase local pressure at user $\mathrm{B}$ by a booster pump. The other is to reduce pressure $\mathrm{P}_{\mathrm{A}}$ and $\mathrm{P}_{\mathrm{C}}$ by installing pressure reducing valves at user $\mathrm{A}$ and $\mathrm{C}$ without lowering $\mathrm{P}_{0}$.

Although Figure 1 shows a case involving a single pipeline, the situation is similar for a real water distribution pipe network. Water pressure is closely related to ground topography, especially in hilly cities. Not all pipes can maintain a proper range of water pressure at the same time by regulating pumps only. There are always some pipes having higher pressure while others have lower pressure. The solutions are also similar to the example in Figure 1: either the areas with low pressure are pressure-boosted or the areas with high pressure are pressure-reduced. In general, variation in ground topography introduces difficulties in the operation of pumps, especially for large water distribution networks with multiple water plants.

For a water supply system with single water plant, water plant pressure can be easily controlled by regulating the pumps. However, for a water supply system with multiple water plants, water pressure regulation becomes extremely complex. The pressure in a pipe network is the joint result of all pump stations, which makes it difficult to precisely regulate the water pressure in the pipe network. Identifying the service area of each plant is essential to manage its water pressure. The service area of a water plant is dependent on several factors, among which ground topography plays an important role.

Therefore, partitioning a complex water distribution network into several sub-networks according to the urban topography will benefit the regulation of water pressure at pump stations and reduce water loss and energy consumption in the pipe network. The idea is that the water pressure of areas with different topography should be managed separately by isolating them from the whole network in order to obtain a spatially even distribution of water pressure.

\subsection{Pipe Network Management Considering Spatial Dif- ferences of Water Use}

Besides the topography, the spatial distribution of water use categories is another factor influencing the water pressure of a pipe network. Different users have different water demand characteristics (Aquacraft Inc., 2011; Singh and Turkiya, 2013). According to the differences in consumption patterns, end users can be classified into categories. Figure 2 shows the hourly water demand profiles of four typical categories, describing the percentage of water consumption in each hour of one day (Aquacraft Inc., 2011).

Flow and pressure interact with each other in a water distribution network. According to the Darcy-Weisbach equation (Equation (1)), the head loss along a pipe is positively related to flow velocity. 


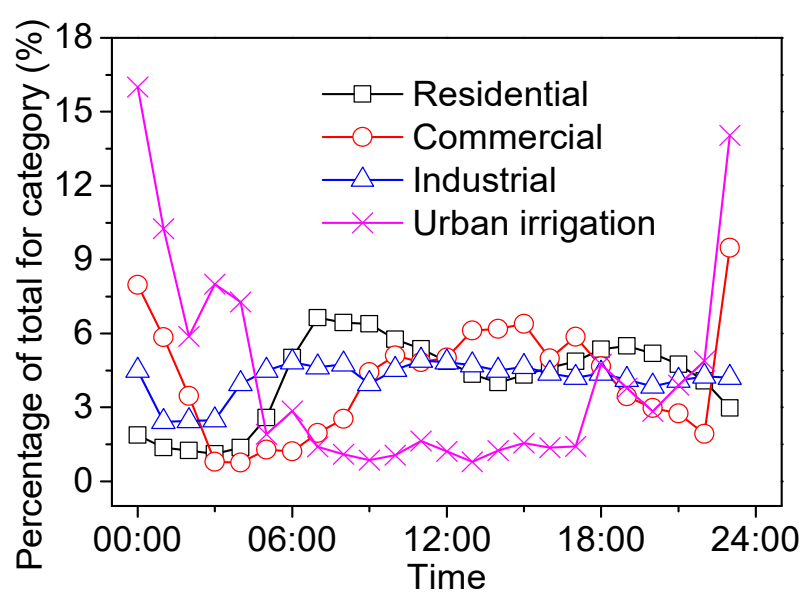

Figure 2. Water demand profiles of four typical categories.

$h_{f}=f_{D} \cdot \frac{L}{D} \cdot \frac{V^{2}}{g}$

where $h_{f}$ is the head loss due to friction; $f_{D}$ is a dimensionless coefficient called the Darcy friction factor; $L$ is the length of the pipe; $D$ is the hydraulic diameter of the pipe; $V$ is the average velocity of the flow; and $g$ is the local acceleration due to gravity.

Given the physical conditions of a pipe network, pressure variation is exclusively influenced by the flow at the pipe ends, i.e. different water demand, and by the pump regulation. Figure 3 illustrates the pressure response to the flow changes of a DMA in the water pipe network of Beijing, which is a typical residential area. It clearly shows that pressure is low at the water demand peaks and high during the low demand periods. Therefore, the water demand of end users must be accounted for when investigating the possibility of water pressure reduction for water loss mitigation.

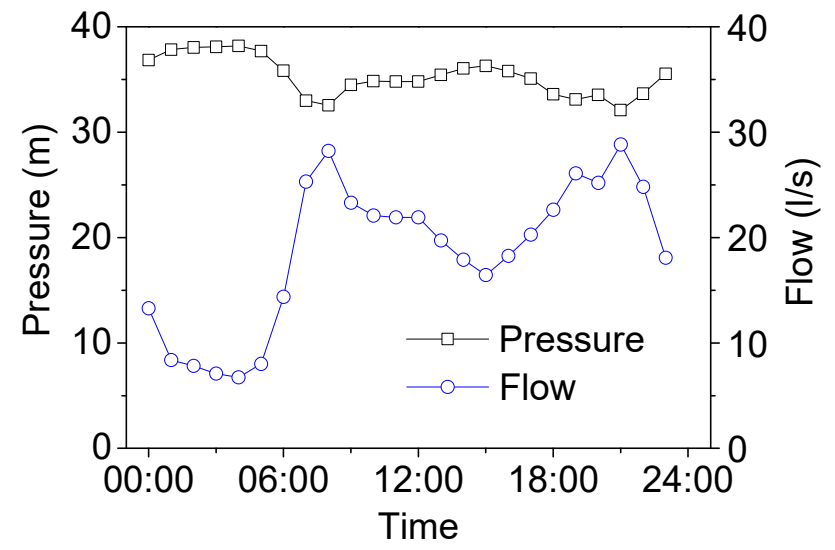

Figure 3. Pressure-flow relationship in a Beijing DMA.

Although there exist different categories of water use, and each category has a distinct water demand pattern, total water flow is the joint result of these patterns combined. It becomes impossible to reasonably regulate the water pressure of a pipe network based on the combined water flow variations. Figure 4 illustrates the phenomenon through a hypothesized pipe network, where water pressure at the water plant is assumed to be constant with time. The water demand patterns of DMA 1 and DMA 2, measured at locations A and B, are shown in curves FA and FB, respectively. They are assumed to be perfectly opposite, such that the sum of water demand of DMA 1 and DMA 2 at any time equals a constant, as shown in curve FC. PA, PB and PC are the corresponding water pressures. It is obvious that PA and PB are time-varying, because the flows (FA and FB) are time-varying. But pressure at node $\mathrm{C}$ (PC) does not vary with time because the flow (FC) is constant. Therefore, if the different water demand patterns (DMA 1 and DMA 2) are combined, their pressure fluctuations cannot be observed. Thus, pressure management (cutting down excess pressure when flow is low) becomes impossible.

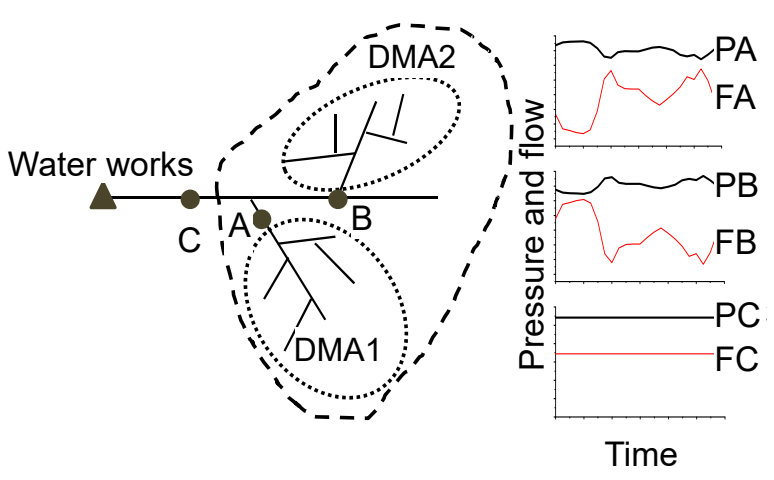

Figure 4. Pressure and flow change patterns of different pipe network sections (PA, PB, PC are pressures at node A, B and $\mathrm{C}$, respectively; FA, FB and FC are the corresponding flows).

Separation of water users by their water demand patterns, as shown by DMA 1 and DMA 2 in Figure 4, would be helpful to determine the characteristics of flow change (FA and FB in Figure 4) and water pressure changes (PA and PB in Figure 4). This could increase the suitability of pressure regulation, such as installing pressure regulation devices at nodes $\mathrm{A}$ and $\mathrm{B}$ to cut excess pressure. Therefore, partitioning a large pipe network into small sub-networks according to their water demand patterns is an effective way to manage water pressure. The question is whether the end users holding similar water demand patterns are geographically adjacent to each other. When planning the landscape of a city, the functions of each area are usually predetermined. In other words, when an urban landscape is formed, water users with similar water demand patterns are already naturally gathered together. However, it should be noted that in some cases, DMAs with similar water demand patterns may have different measured flows due to discrepant water loss. Thus, DMA planning and consequent water loss reduction strategies could be further optimized by considering pipe characteristics after considering the water demand patterns of end users. 


\subsection{Management of Water Distribution Networks Empha- sizing Urban Landscape Factors}

Urban topography influences the spatial pattern of averaged water pressure, and water user layout influences the temporal variation of water pressure. Therefore, effective management of water pressure should focus on these two aspects, which leads to a two-level management strategy for the water distribution pipe network, as shown in Figure 5.

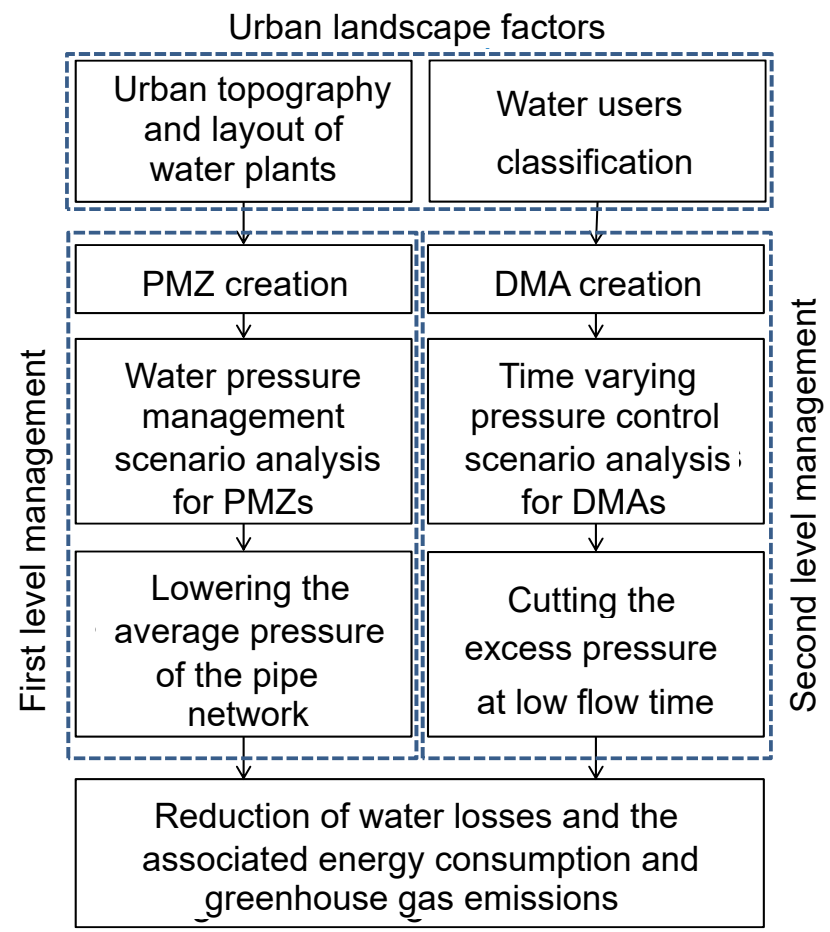

Figure 5. Flowchart of the proposed two-level water pipe network management.

First, the possibility of dividing a pipe network into several pressure management zones (PMZs) should be assessed according to the urban topography and location(s) of water plant(s). In this research, a PMZ is defined as a sub-network much larger than a DMA where water pressure can be regulated by pumps in the water plant. Water pressure between PMZs should be significantly different. The pressure management strategies for these PMZs are then designed and analyzed according to the cost-benefit principle. Costs include equipment investment (pumps, valves, and controllers), and benefits include reduction of water loss, energy consumption and greenhouse gas emissions. Once the PMZs are made, average water pressure can be lowered overall. However, there is still the potential to reduce excess water pressure during low flow periods, such as midnight to early morning in residential areas, using DMAs. Therefore, the next step is to further partition the network of PMZs into DMAs. Basic principles to establish DMAs can be found in the literature (Farley et al., 2008), in which the key feature is that water users in a DMA should have a similar water demand pattern. Finally, the construction of PMZs and DMAs and especially the pressure management of these sub-networks should be optimized over time because the hydraulic status of the pipe network changes with the implementation of zoning management.

The benefit of the proposed two-level management is actually not limited to the abovementioned pressure reduction. Because pipe network partitioning considers the urban landscape, it implies that the areas of the pipe network (PMZ or DMA) usually have different landscape properties, such as the elevation, land use type, soil moisture, and ground traffic load. These factors, together with physical properties such as age and material of the pipes, influence the probability of pipe breaks, which is the primary parameter of water loss besides water pressure. It is, therefore, useful to investigate the relationship between pipe break probability and the environmental factors of an urban landscape, and thus optimize pipe break detection. Combining pipe break detection and water pressure management, water loss can be effectively reduced.

\subsection{Case Study Area}

The proposed water distribution management method was applied in Beijing, China. The network has a total of more than $8000 \mathrm{~km}$ of pipes and 10 water plants. Non-revenue water is about $18 \%$ of the total water supply, which amounts to 188 million $\mathrm{m}^{3}$ per year. In recent years, the Beijing Waterworks Group has taken great efforts to reduce water loss. However, because the network is looped and the ground elevation varies spatially (high in the northwest and low in the southeast), it is very difficult to effectively manage the network, especially with regards to water pressure. Figure 6 shows the geographic layout of the pipe network skeleton (pipes with diameters larger than or equal to $400 \mathrm{~mm}$ ) and the water pressure ranges (from 19.8 to $41.5 \mathrm{~m}$ ). It can be seen that there is high potential to manage the water supply in an energy-efficient and environmentally friendly manner, taking into account the spatial variation of urban topography.

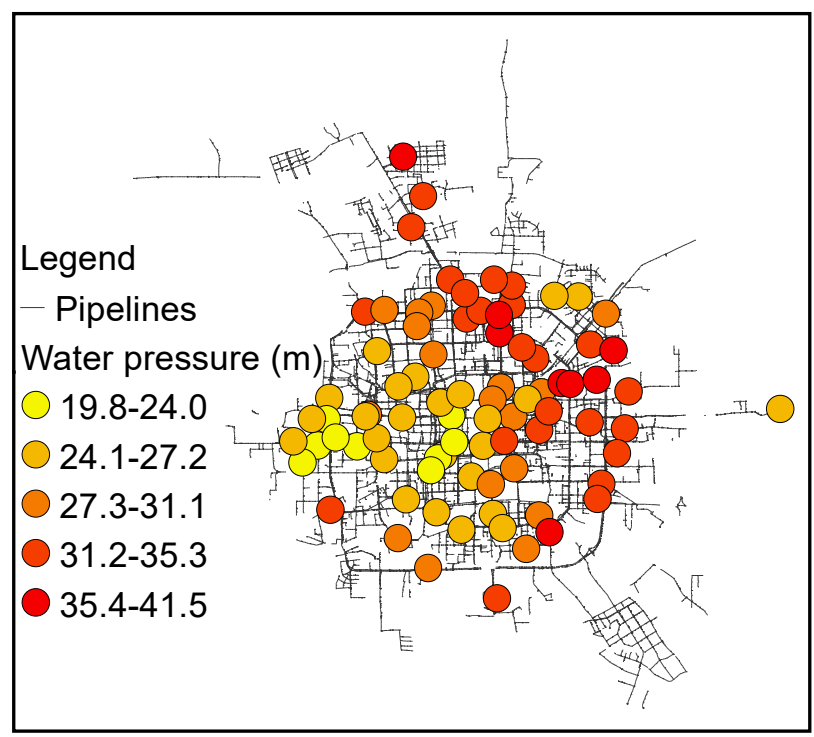

Figure 6. Trunk mains and monitored water pressure of Beijing water supply network. 


\section{Results and Discussions}

\subsection{Partitioning of the Pipe Network}

The pipe network was planned to be divided into five large PMZs according to urban topography and the distribution of water plants in Beijing city (Figure 7). The PMZ isolation was achieved by closing the critical valves on the trunk mains. Since the influence of pump regulation in the water plants was restricted to smaller sub-networks instead of the whole network, the pressure of PMZ would be much more sensitive to pump regulation, which made it easier to optimize the pump regulation according to the pressure in the subnetworks.

Pressure management was conducted in one PMZ (PMZ 1) by the end of the year 2015. The water plant in this area (water plant A in Figure 7) supplied water to PMZ 1, PMZ 2 and PMZ 4 through path $\mathrm{A}, \mathrm{B}$ and $\mathrm{C}$. Because the ground elevation of the area along path $\mathrm{A}$ is higher than other areas, the water pressure in this area was much lower (see Figure 6). Even if the pressure in water plant A was raised, the water pressure in the area along path A could not rise effectively because most water flowed to PMZ 2 and PMZ 4 through path B. Therefore, a critical valve on the trunk mains was closed to cut off flow path B (see Figure 7). As a result, water from plant A was mainly restricted in PMZ 1. Consequently, pressure of PMZ 1 could be easily regulated by water plant A.

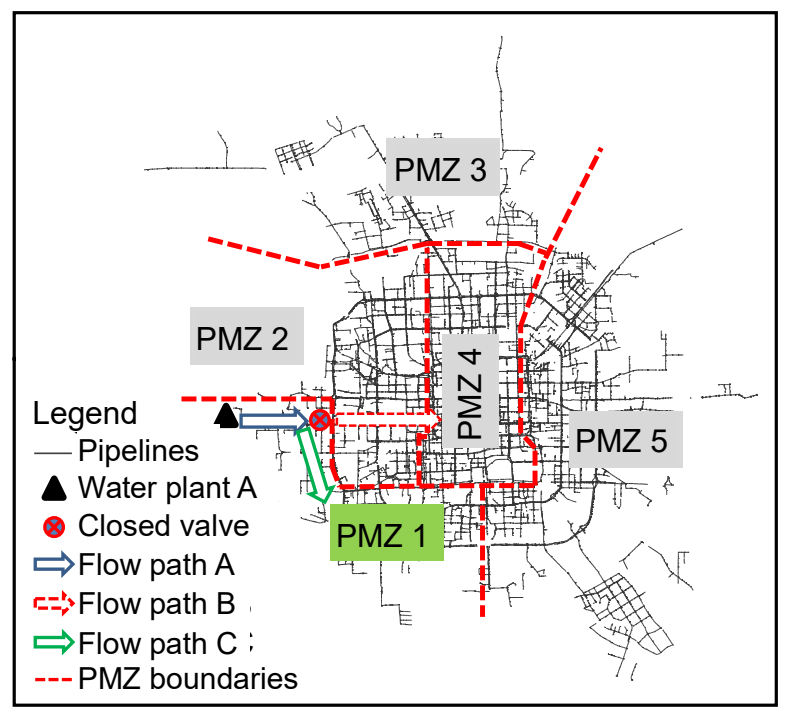

Figure 7. Designed PMZs in water pipe network of Beijing.

Small zones (DMA) were also established according to water use characteristics and local topography (Figure 8). By the end of the year 2015, a total number of 823 DMAs were planned, among which 290 DMAs were implemented. The DMA isolation was accomplished by closing the boundary valves with one or two inlets remaining.

The water pressure of DMAs was controlled by PRVs if necessary. In this case, 10 DMAs had been pressure-controlled by PRVs, 9 of which were located in the northern part of the network where the water pressure is relatively high (DMAs_A, black circles in Figure 8). The rest one was locat- ed in a sub-network in the west of the pipe network of Beijing, which was not shown in Figure 8. Some DMAs seemed to be out of the pipe network in Figure 8, because pipes with diameters smaller than $400 \mathrm{~mm}$ were not shown.

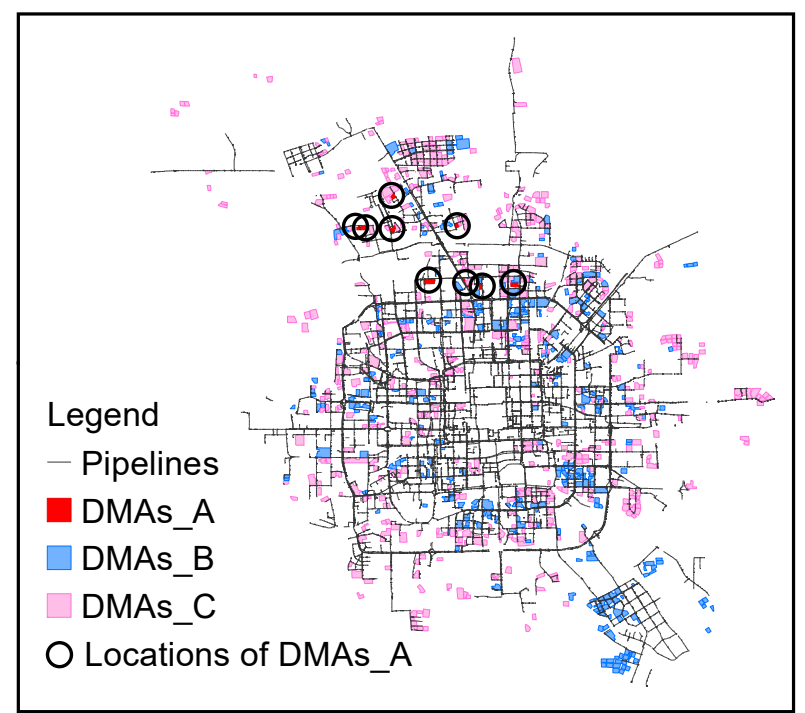

Figure 8. Designed DMAs in water pipe network of Beijing (DMAs_A: pressure-reduced DMAs; DMAs_B: implemented DMAs; DMAs_C: planned DMĀs.).

Calculations and experiments were conducted to decide which valves should be closed before the implementation of the PMZs and DMAs. There were mainly two concerns: water pressure and water quality. The implementation of the PMZs or DMAs was considered valid only if acceptable water pressure could be achieved while also maintaining water quality meeting the national drinking water standards.

\subsection{Benefits Obtained from Two-level Management of the Pipe Network}

The direct benefit obtained is the water saving due to the pressure management. It is recognized that pressure management is the most effective way to reduce water loss, especially for small leaks that cannot be detected by leakage detection devices, known as background leakage. Table 1 shows the two-week average flow and water pressure before and after the pressure reduction in the 10 DMAs. It clearly shows that water was saved after the pressure reduction, with an average of $0.11 \mathrm{l} / \mathrm{s}$ per kilometre of pipe per meter of water pressure drop.

However, the effectiveness of pressure control differs between DMAs. The reason is that each DMA has intrinsic characteristics in terms of pipe material, pipe age, pipe length, and number of service connections. It is, therefore, important to further investigate how the DMA characteristics influence water savings through pressure management, based on which the pressure control plan for each DMA could be optimized. In fact, this is one of the main objectives of zoning management of the pipe network; however, the data was insufficient to support the analysis in this study. 
Table 1. Water Savings of DMAs through Pressure Management

\begin{tabular}{lllllll}
\hline \multirow{2}{*}{ DMA No. } & \multirow{2}{*}{ Pipe length $(\mathrm{km})$} & \multicolumn{2}{l}{ Average pressure $(\mathrm{m})$} & \multicolumn{2}{l}{ Average flow $(\mathrm{l} / \mathrm{s})$} & \multirow{2}{*}{ Water saving* $(1 / \mathrm{s} / \mathrm{km} / \mathrm{m})$} \\
\cline { 3 - 6 } & & before & after & before & after & 0.08 \\
\hline 1 & 2.23 & 33.51 & 30.55 & 5.56 & 5.03 & 0.19 \\
2 & 1.28 & 30.63 & 28.51 & 3.87 & 3.35 & 0.30 \\
3 & 3.17 & 30.43 & 28.12 & 12.56 & 10.39 & 0.08 \\
4 & 2.32 & 35.25 & 30.05 & 5.32 & 4.37 & 0.12 \\
5 & 4.25 & 33.98 & 30.23 & 10.25 & 8.39 & 0.06 \\
6 & 1.82 & 32.37 & 28.69 & 6.95 & 6.58 & 0.07 \\
7 & 3.71 & 32.31 & 26.74 & 14.78 & 13.29 & 0.16 \\
$8^{* *}$ & 7.2 & 37.14 & 32.52 & 21.55 & 16.32 & 0.01 \\
9 & 3.56 & 41.73 & 34.45 & 5.5 & 5.21 & 0.08 \\
10 & 2.33 & 41.33 & 29.19 & 30.86 & 28.49 & 0.11 \\
Average & 3.19 & 34.87 & 29.91 & 11.72 & 10.14 & \\
\hline
\end{tabular}

*in term of per kilometer of pipe per meter of water pressure reduction.

**This DMA was not shown in Figure 8.

If the average water saving of the DMAs in Table $1(0.11$ 1/s per kilometre of pipe per meter of water pressure reduced) is simply extrapolated to all the pipes with diameter no larger than $300 \mathrm{~mm}$ of the whole network $(4863 \mathrm{~km})$, it is estimated that 16.9 million $\mathrm{m}^{3}$ of water could be saved each year if the water pressure is reduced by $1 \mathrm{~m}$ on average. Since the pipe diameters of DMAs are generally no larger than $300 \mathrm{~mm}$, only these pipes were considered when extrapolating the water saving results from experimental DMAs to the whole network.

With the implementation of PMZs, the excessive water pressure was lowered by regulating the pumps in the water plants, which reduced water loss from pipes with diameter larger than $300 \mathrm{~mm}$. This implies the total water saving is larger than that estimated based on the DMA pressure control.

The zoning management of the pipe network also provides other benefits. Firstly, it allows a rapid awareness of new breaks in pipe by analyzing the flow changes of the sub-networks, thus shortening the duration of the breaks so as to reduce water loss. Secondly, it allows for optimization of water loss control priorities considering the properties of the sub-networks, which would undoubtedly improve the water loss reduction efficiency. Lastly, it facilitates the performance evaluation of the workforce of the water supply company. After partitioning a network into many sub-networks, the responsibility of reducing water loss could be assigned to specific persons, which could be a way to improve their work efficiencies.

\subsection{Limitations of Two-level Management and Recom- mendations for Future Study}

The proposed two-level management of water distribution networks provides general guidance for the water supply industry. According to its application to the water distribution network of Beijing, it can help reduce water loss and energy consumption. It is particularly applicable for poorly designed or rapidly expanded pipe networks, as often seen in developing countries. However, the method did not include any mathematical calculation or optimization in the partitioning of the pipe network. This is the main drawback of the present study, but it can be overcome in the future when pipe network data are sufficient for numerical modelling and optimization.
The partitioning of a network could possibly decrease the reliability of the pipe network to some extent because it violates the design criteria of looped pipe networks. In the application of the proposed method, PMZs and DMAs must be carefully designed to ensure reliable water supply; for example, backup inlets for sub-networks. Furthermore, partitioning a network into sub-networks might lead to problems with water quality deterioration or insufficient pressure due to the formation of dead-end sections. Therefore, water quality and pressure must be monitored when applying the proposed method. If necessary, network partitioning should be modified over time according to monitored water quality and pressure.

In the future, efforts should be taken to (1) develop an early warning method for new breaks in DMAs based on the analysis of flow data; (2) define water loss reduction targets for individual DMAs based on the relationship between flow and DMA properties; (3) optimize pump regulation and RPV settings to obtain reasonable spatiotemporal distribution of water pressure; and (4) develop an integrated decision support system for pressure management.

\section{Conclusions}

Reducing water loss and energy consumption are two important issues in the global water and energy crisis. The relationships between water loss from water distribution networks and urban landscape factors, particularly urban topography and water-use layout, were reviewed in this study. It was found that urban topography significantly influenced the spatial variation of average water pressure, and water-use layout influenced the temporal variation of water pressure. Based on these findings, a two-level strategy for water distribution network management was proposed. The first level includes the implementation of PMZs, accounting for the spatial variations of urban topography, to control the averaged water pressure. The second level includes the implementation of DMAs, accounting for the daily water demand variations of end-users, to reduce excessive pressure during low flow hours. In addition to water pressure management, pipe break detection can also benefit from the proposed two-level management of the water distribution network. The effectiveness of the proposed management strategy was demonstrated by its application to the water distribution network of Beijing, where it was esti- 
mated that more than 16.9 million $\mathrm{m}^{3}$ of water could be saved per year with a one-meter drop in the average water pressure. In conclusion, water distribution network management is not only a municipal engineering issue, but also an urban landscape related issue. Considering urban landscape factors in water distribution network design and operation can significantly reduce water loss and associated energy consumption, as well as greenhouse gas emissions.

Acknowledgments. This research was supported by Ministry of Sciences and Technology of the People's Republic of China (No. 2012ZX07408-002) and the National Natural Science Foundation of China (No. 51309216). The authors are grateful to Dr. Christine Watts for proofreading the English of the manuscript.

\section{References}

Birge, J.R. and Louveaux, F.V. (1988). A multicut algorithm for two-stage stochastic linear programs. Eur. J. Oper. Res., 34(3), 384-392. http://dx.doi.org/10.1016/0377-2217(88)90159-2

Aksela, K., Aksela, M., and Vahala, R. (2009). Leakage detection in a real distribution network using a SOM. Urban Water J., 6(4), 279-289. http://dx.doi.org/10.1080/15730620802673079

Aquacraft Inc. (2011). Embedded energy in water studies study 3: end-use water demand profiles, California: California Public Utilities Commission Energy Division. http://www.cpuc.ca. gov/PUC/ energy/Energy+Efficiency/EM+and+V/Embedded+Energy+in+ Water+Studies1_and_2.htm.

Araujo, L., Ramos, H., and Coelho, S. (2006). Pressure control for leakage minimisation in water distribution systems management Water Resour. Manage., 20(1), 133-149. http://dx.doi.org/10.1007/ s11269-006-4635-3

Berardi, L., Kapelan, Z., Giustolisi, O., and Savic, D.A. (2008). Development of pipe deterioration models for water distribution systems using EPR. J. Hydroinf., 10(3), 113-126. http://dx.doi.org/ 10.2166 /hydro.2008.012

Buchberger, S. and Nadimpalli, G. (2004). Leak estimation in water distribution systems by statistical analysis of flow readings. $J$. Water Resour. Plann. Manage., 130(4), 321-329. http://dx.doi.org/10. 1061/(ASCE)0733-9496(2004)1 30:4(321)

Cai, Y. P., Huang, G. H., Yang, Z. F., Lin, Q. G., and Tan, Q. (2009). Community-scale renewable energy systems planning under uncertainty - An interval chance-constrained programming approach. Renew. Sust. Energ. Rev., 13(4), 721-735. https://doi.org/10.1016/ j.rser. 2008.01.008

Cai, Y. P., Huang, G. H., Yang, Z. F., and Tan, Q. (2009). Identification of optimal strategies for energy management systems planning under multiple uncertainties. Appl. Energ, 86(4), 480-495. https: //doi.org/10.1016/j.apenergy.2008.09.025

Carrión, A., Solano, H., Gamiz, M., and Debón, A. (2010) Evaluation of the reliability of a water supply network from right-censored and left-truncated break data. Water Resour. Manage., 24(12), 2917-2935. http://dx.doi.org/10.1007/s11269-010-9587-y

Coombes, P.J., Argue, J.R., and Kuczera, G. (2000). Figtree Place: A case study in water sensitive urban development (WSUD). Urban Water J., 1(4), 335-343. http://dx.doi.org/10.1016/S1462-0758(00) 00027-3

Di Nardo, A. and Di Natale, M. (2011). A heuristic design support methodology based on graph theory for district metering of water supply networks. Eng. Optimiz., 43(2), 193-211. http://dx.doi.org/ $10.1080 / 03052151003789858$

Di Nardo, A., Di Natale, M., Musmarra, D., Santonastaso, G.F., Tzatchkov, V., and Alcocer-Yamanaka, V.H. (2014). A district sectorization for water network protection from intentional contamination. Procedia Eng., 70, 515-524. http://dx.doi.org/10.1080/030 52151003789858

Doleac, M.L., Lackey, S.L., and Bratton, G. (1980). Prediction of time-to-failure for buried cast iron pipes, Proc. of the American Water Works Association Annual Conference, Denver, 21-28. http://dx.doi.org/10.1016/j.proeng.2014.02.057
Dridi, L., Mailhot, A., Parizeau, M., and Villeneuve, J.P. (2009). Multiobjective approach for pipe replacement based on bayesian inference of break model parameters. J. Water Resour. Plann. Manage., 135(5), 344-354. http://dx.doi.org/10.1061/ (ASCE)07 33-9496(2009)135:5(344)

Du, N., Ottens, H., and Sliuzas, R. (2010). Spatial impact of urban expansion on surface water bodies: A case study of Wuhan, China. Landscape Urban Plann., 94(3), 175-185. http://dx.doi.org/10.10 16/j.landurbplan.2009.10.002

Fan, Y. R. and Huang, G. H. (2012). A Robust Two-Step Method for Solving Interval Linear Programming Problems within an Environmental Management Context. J. Environ. Inf., 19(1). https:// doi.org/10.3808/jei.201200203

Farley, M., Wyeth, G., Ghazali, Z.B.M., Istandar, A., and Singh, S. (2008). The manager's non-revenue water handbook: a guide to understanding water losses, Ranhill Utilities Berhad and the United States Agency for International Development.

Ferguson, B.C., Frantzeskaki, N., and Brown, R.R. (2013). A strategic program for transitioning to a Water Sensitive City. Landscape Urban Plann., 117, 32-45. http://dx.doi.org/10.1016/j.landurbplan. 2013.04.016

Fontana, M. and Morais, D. (2013). Using Promethee V to select alternatives so as to rehabilitate water supply network with detected leaks. Water Resour. Manage., 27(11), 4021-4037. http://dx. doi.org/10.1007/s11269-013-0393-1

Friedrich, E. (2002). Life-cycle assessment as an environmental management tool in the production of potable water. Water Sci. Technol., 46(9), 29-36.

GEI Consultants/Navigant Consulting Inc. (2010a). Embedded energy in water studies study 1: State-wide and regional water-energy relationship, California: California Public Utilities Commission Energy Division. http://www.cpuc.ca.gov/PUC/energy/Energy+Efficiency/EM+and $+\mathrm{V} /$ Embedded+Energy+in+Water+Studies1_ and 2.htm.

GEI Consultants/Navigant Consulting Inc. (2010b). Embedded energy in water studies study 2: Water agency and function component study and embedded energy-water load profiles, California: California Public Utilities Commission Energy Division. http://www. cpuc.ca.gov/PUC/energy/Energy+Efficiency/EM+and+V/Embedd ed+Energy+in+Water+Studies1_and_2.htm.

Girard, M. and Stewart, R.A. (2007). Implementation of pressure and leakage management strategies on the Gold Coast, Australia: Case study. J. Water Resour. Plann. Manage., 133(3), 210-217. http://dx.doi.org/10.1061/(ASCE)0733-9496(2007)133:3(210)

Gomes, R., Marques, A.S.A., and Sousa, J (2013). Distrcit metered areas design under different decision maker's options: cost analysis. Water Resour. Manage., 27(13), 4527-4543. http://dx.doi.org/ 10.1007/s11269-013-0424-y

Islam, M.S., Sadiq, R., Rodriguez, M.J., Francisque, A., Najjaran, H., and Hoorfar, M. (2011). Leakage detection and location in water distribution systems using a fuzzy-based methodology. Urban Water J., 8(6), 351-365. http://dx.doi.org/10.1080/1573062X.2011.61 7829

James, K., Campbell, S.L., and Godlove, C.E. (2002). Watergy: Taking advantage of untapped energy and water efficiency opportunities in municipal water systems, Alliance to Save Energy, Washington DC, USA.

Lambert, A. (2000). What do we know about pressure-leakage relationships in distribution systems? Proc. Of IWA Specialized Conference: System Approach to Leakage Control and Water Distribution Systems Management, Brno, Czech Republic, 89-96.

Li, Y. P., Huang, G. H., and Chen, X. (2011). Planning regional energy system in association with greenhouse gas mitigation under uncertainty. Appl. Energ., 88(3), 599-611. https://doi.org/10.1016/j. apenergy.2010.07.037

Li, Y. P., Huang, G. H., Huang, Y. F., and Zhou, H. D. (2009). A multistage fuzzy-stochastic programming model for supporting sustainable water-resources allocation and management. Environ. Model. Softw., 24(7), 786-797. https://doi.org/10.1016/j.envsoft. 2008.11.008 
Li, Y. P., Huang, G. H., and Nie, S. L. (2006). An interval-parameter multi-stage stochastic programming model for water resources management under uncertainty. Adv. Water. Resour., 29(5), 776789. https://doi.org/10.1016/j.advwatres.2005.07.008

Luo, B., Maqsood. I., Yin, Y.Y., Huang, G.H., and Cohen, S.J. (2003). Adaption to climate change through water trading under uncertainty-An inexact two-stage nonlinear programming approach. $J$. Environ. Inf., 2(2), 58-68. http://dx.doi.org/10.3808/jei.200300022

Luong, H.T. and Nagarur, N.N. (2005). Optimal maintenance policy and fund allocation in water distribution networks. J. Water Resour. Plann. Manage., 131(4), 299-306. http://dx.doi.org/10.1061/(AS CE)0733-9496(2005)131:4(299)

Lv, Y., Huang, G.H., Li, Y.P., Yang, Z.F., Liu, Y., and Cheng, G.H. (2010). Planning regional water resources system using an interval fuzzy bi-level programming method. J. Environ. Inf., 16(2), 43-56. http://dx.doi.org/10.3808/jei.201000177

Lyons, E., Zhang, P., Benn, T., Sharif, F., Li, K., Crittenden, J., Costanza, M., and Chen, Y. (2009). Life cycle assessment of three water supply systems: importation, reclamation and desalination. Water Sci. Technol. Water Supply, 9(4), 439-448. http://dx.doi.org/ 10.2166/ws.2009.534

Marunga, A., Hoko, Z., and Kaseke, E. (2006). Pressure management as a leakage reduction and water demand management tool: The case of the city of Mutare, Zimbabwe. Phys. Chem. Earth, 31(15-16), 763-770. http://dx.doi.org/10.1016/j.pce.20 06.08.032

Misiunas, D., Vítkovský, J., Olsson, G., Simpson, A., and Lambert, M. (2005). Pipeline break detection using pressure transient monitoring. J. Water Resour. Plann. Manage., 131(4), 316-325. http:// dx.doi.org/10.1061/(ASCE)0733-9496 (2005)131:4(316)

Mo. W., Zhang, Q., Mihelcic, J.R., and Hokanson, D.R. (2011). Embodied energy comparison of surface water and groundwater supply options. Water Res., 45(17), 5577-5586. http://dx.doi.org/10. 1016/j.watres.2011.08.016

Morison, P.J. and Brown, R.R. (2011). Understanding the nature of publics and local policy commitment to Water Sensitive Urban Design. Landscape Urban Plann., 99(2), 83-92. http://dx.doi.org/ 10. 1016/j.landurbplan.2010.08.019

Mutikanga, H., Sharma, S., and Vairavamoorthy, K. (2013). Methods and tools for managing losses in water distribution systems. J. Water Resour. Plann. Manage., 139(2), 166-174. http:// dx.doi org/10.1061/(ASCE)WR.1943-5452.000024 5

Nazif, S., Karamouz, M., Tabesh, M., and Moridi, A. (2010). Pressure management model for urban water distribution networks. Water Resour, Manage., 24(3), 437-458. http://dx.doi.org/10.1007/s1126 9-009-9454-x

Olsen, D.R., Dickson, S.E., and Baetz, B.W. (2006). Decision support system for rural water supply in the Nilgiris District of south India. J. Environ. Inf., 7(1), 1-13. http://dx.doi.org/10.3808/jei.2006000 62

Ontario Ministry of the Environment. (2008). Design guidelines for drinking-water systems, Ontario, Canada.

Park, S., Choi, C., Kim, J., and Bae, C. (2010), Evaluating the economic residual life of water pipes using the proportional hazards model. Water Resour. Manage., 24(12), 3195-3217. http://dx.doi. org/10.1007/s11269-010-9602-3

Park, S., Jun, H., Kim, B., and Im, G. (2008). Modeling of water main failure rates using the Log-linear ROCOF and the Power Law process. Water Resour. Manage., 22(9), 1311-1324. http:// dx.doi. org/10.1007/s11269-007-9227-3

Park, S. and Loganathan, G. (2002). Methodology for economically optimal replacement of pipes in water distribution systems: 1 . Theory. KSCE J. Civil Eng., 6(4), 539-543. http://dx.doi.org/10. 1007/BF02842007

Puust. R., Kapelan, Z., Savic, D.A., and Koppel, T. (2010). A review of methods for leakage management in pipe networks. Urban Water J., 7(1), 25-45. http://dx.doi.org/10.1080/157306 21003610878

Racoviceanu, A.I., Karney, B.W., Kennedy, C.A., and Colombo, A.F. (2007). Life-cycle energy use and greenhouse gas emissions inventory for water treatment systems. J. Infrastruct. Syst., 13(4), 261-270. http://dx.doi.org/10.1061/(ASCE)1076-0342(2007)13:4 (261)
Rahmani, M.A. and Zarghami, M. (2015). The use of statistical weather generator, hybrid data driven and system dynamics models for water resources management under climate change. J. Environ. Inf., 25(1), 23-35. http://dx.doi.org/10.3808/jei.201400285

Reis, L., Porto, R., and Chaudhry, F. (1997). Optimal location of control valves in pipe networks by genetic algorithm. J. Water Resour. Plann. Manage., 123(6), 317-326. http://dx.doi.org/10.1061/ (ASCE)0733-9496(1997)123:6(317)

Sousa, J., Muranho, J., Sá Marques, A., and Gomes, R. (2014). WaterNetGen HELPS C-Town. Procedia Eng., 89, 103-110. http:// dx.doi.org/10.1016/j.proeng.2014.11.165

Shamir, U. and Howard, C. (1979). An analytical approach to scheduling pipe replacement. J. Am. Water Works Assoc., 71(5), 248258. http://www.jstor.org/stable/41270297

Singh, O. and Turkiya, S. (2013). A survey of household domestic water consumption patterns in rural semi-arid village, India. GeoJournal, 78(5), 777-790. http://dx.doi.org/10.1007/s10708-012-94 $65-7$

Stokes, J.R. and Horvath, A. (2006). Life cycle energy assessment of alternative water supply systems. Int. J. Life Cycle Assess., 11(5), 335-343. http://dx.doi.org/10.1065/lca2005.06.214

Stokes, J.R., and Horvath, A. (2009). Energy and air emission effects of water supply. Environ. Sci. Technol., 43(8), 2680-2687. http:// dx.doi.org/10.1021/es801802h

Stokes, J.R., Horvath, A., and Sturm, R. (2013). Water loss control using pressure management: life-cycle energy and air emission effects. Environ. Sci. Technol., 47(19), 10771-10780. http://dx.doi. org/10.1021/es4006256

$\mathrm{Su}$, L.Y., Christensen, P., and Liu, J.L. (2013). Comparative study of water resource management and policies for ecosystems in China and Denmark. J. Environ. Inf., 21(1), 72-83. http://dx.doi.org/ $10.3808 /$ jei.201300234

Tabesh, M., and Saber, H. (2012). A prioritization model for rehabilitation of water distribution networks using GIS. Water Resour. Manage., 26(1), 225-241. http://dx.doi.org/10.1007/s11269-0119914-y

Wang, L.Z., Fang, L., and Hipel, K.W. (2003). Water resources allocation: A cooperative game theoretic approach. J. Environ. Inf., 2(2), 11-22. http://dx.doi.org/10.3808/jei.200300019

Wong, T. and Brown, R. (2009). The water sensitive city: principles for practice. Water Sci. Technol., 60(3), 673-682. http://dx.doi. org/10.2166/wst.2009.436

Wu, Z.Y. (2009). Unified parameter optimisation approach for leakage detection and extended-period simulation model calibration. Urban Water J., 6(1), 53-67. http://dx.doi.org/10.1080/157306208 02541631

WWAP (World Water Assessment Programme). (2006). World water development report 2: Water: A shared responsibility, Paris/New York, UNESCO/Berghahn Books.

Xu, Q., Chen, Q.W., and Li, W.F. (2011a). Application of genetic programming to modeling pipe failures in water distribution systems. J. Hydroinf., 13(3), 419-428. http://dx.doi.org/10.2166/hy dro.2010.189

Xu, Q., Chen, Q.W., Li, W.F., and Ma, J.F. (2011b). Pipe break prediction based on evolutionary data-driven methods with brief recorded data. Reliab. Eng. Syst. Saf., 96(8), 942-948. http://dx. doi.org/10.1016/j.ress.2011.03.010

Xu, Q., Chen, Q.W., Ma, J.F., and Blanckaert, K. (2013). Optimal pipe replacement strategy based on break rate prediction through genetic programming for water distribution network. J. Hydroenviron. Res., 7(2), 134-140. http://dx.doi.org/10.1016/j.jher.2013. 03.003

Xu, Q., Chen, Q.W., Ma, J.F., Blanckaert, K., and Wan Z.H. (2014a). Water saving and energy reduction through pressure management in urban water distribution networks. Water Resour. Manage., 28(11), 3715-3726. http://dx.doi.org/10.100 7/s11269-014-0704-1

Xu, Q., Liu, R.P., Chen, Q.W., and Li, R.N. (2014b). Review on water leakage control in distribution networks and the associated environmental benefits. J. Environ. Sci.-China, 26(5), 955-961. http://dx.doi.org/10.1016/S1001-0742(13)60569-0

$\mathrm{Xu}$, Y., Huang, G.H., and Xu, T.Y. (2012). Inexact management modeling for urban water supply systems. J. Environ. Inf., 20(1), 34-43. http://dx.doi.org/10.3808/jei.201200218 